Western University

Scholarship@Western

Education Publications

Education Faculty

2014

\title{
Gauging the effects of exercises on verb-noun collocations
}

Frank Boers

Western University, fboers@uwo.ca

Murielle Demecheleer

Victoria University of Wellington

Averil Coxhead

Victoria University of Wellington

Stuart Webb

The University of Western Ontario, swebb27@uwo.ca

Follow this and additional works at: https://ir.lib.uwo.ca/edupub

Part of the Education Commons

Citation of this paper:

Boers, F., Demecheleer, M., Coxhead, A., \& Webb, S. (2014). Gauging the effects of exercises on verb-noun collocations. Language Teaching Research, 18(1), 50-70. 


\section{Gauging the effects of exercises on verb-noun collocations}

\section{Frank Boers}

Victoria University of Wellington, New Zealand

\section{Murielle Demecheleer}

Victoria University of Wellington, New Zealand

\section{Averil Coxhead}

Victoria University of Wellington, New Zealand

\section{Stuart Webb}

Victoria University of Wellington, New Zealand 


\section{Abstract}

Many contemporary textbooks for English as a foreign language (EFL) and books for vocabulary study contain exercises with a focus on collocations, with verb-noun collocations (e.g. make a mistake) being particularly popular as targets for collocation learning. Common exercise formats used in textbooks and other pedagogic materials require learners to establish appropriate matches between sets of verbs and nouns.

However, matching exercises almost inevitably carry a risk of erroneous connections, and despite corrective feedback these might leave undesirable traces in the learner's memory. We report four small-scale trials (total $n=135$ ) in which the learning gains obtained from verbnoun matching exercises are compared with the learning gains obtained from a format in which the target collocations are presented to the learners as intact wholes. Pre-test to post-test gains turned out small in all of the conditions, owing in part to the learners' substitution of initially correct choices by distracters from the exercises. The latter, negative side-effect was attested more often in the matching exercises than in the exercises where the learners worked with collocations as intact wholes.

\section{Keywords}

Collocations, cross association, exercise types, retention, TESOL 


\section{Introduction}

Collocations (e.g. tell lies, heavy rain, deeply religious), alongside many other kinds of lexical phrases, constitute a segment of formulaic language (Wray, 2002), which has gained considerable popularity as a subject of investigation in research on second language acquisition (SLA) (e.g. Schmitt, 2004; Meunier \& Granger, 2008; Wood, 2010) and second language (L2) pedagogy (e.g. Lewis, 1993; Lindstromberg \& Boers, 2008; Nattinger \& DeCarrico, 1992) in recent times. Adequate use of formulaic word strings (which, apart from collocations, 1 include idioms, compounds, phrasal verbs, social routine formulae, proverbs, and standardized similes and binomial phrases) has been shown to help L2 learners come across as proficient in speech (Boers, Eyckmans, Kappel, Stengers, \& Demecheleer, 2006) and in writing (Dai \& Ding, 2010). Unfortunately, acquisition of L2 formulaic sequences seems in general to be a very slow process (Kuiper, Columbus, \& Schmitt, 2009; Li \& Schmitt, 2010), with only highly advanced learners (typically language majors and/or learners having been immersed in the L2 environment for several years) displaying a breadth of knowledge of formulaic language that resembles that of native speakers (Forsberg, 2010; Nekrasova, 2009).

Acquisition of verb-noun collocations (e.g. make a mistake) has been shown to be particularly problematic for (adult) L2 learners. A 
cross-sectional study by Laufer and Waldman (2011), for example, found hardly any difference in productive knowledge of verb-noun collocations between lower and upper intermediate groups of EFL learners. It is most typically the verb in these collocations that learners substitute by an unconventional choice (*do a mistake), and such substitutions are likely to be due to interference from the mother tongue when equivalent first-language nouns collocate with a different verb (Nesselhauf, 2005; Yamashita \& Jiang, 2010).

Several factors may jointly account for the particularly slow uptake of verb-noun collocations by L2 learners. When the collocation consists of words that the learner is already familiar with (e.g. have +dream), a learner is not very likely to attend to the word combination as such. Given the high frequency of the verbs that form part of many collocations, these verbs are probably familiar to the learner and therefore unlikely to attract much attention. Moreover, it is the noun in verb-noun collocations that usually carries most of the semantic weight of the unit, as the verb is often a multi-purpose, semantically rather vague item (e.g. compare make and mistake). This, too, minimizes the need to attend to the verb in order to interpret the phrase. That the verb contributes relatively little to the semantics of some collocations can be illustrated by the near-equivalence of pairs such as you're telling lies and you're lying. 
A further likely cause for erroneous substitutions by learners lies in the lack of distinctiveness of the verbs. Some of the verbs that occur in collocations may be treated as synonyms by the learner (e.g. make and do in make a mess and do damage; tell and say in tell the truth and say a prayer). In a study of adjective-noun collocations, Webb and Kagimoto (2011) report findings that suggest that concurrently encountered collocations that contain semantically similar words (e.g. narrow in narrow escape and slim in slim chance) are especially hard for learners to commit to memory, probably due to the effort that is required to block erroneous cross associations of the synonymous words. Their finding extends those of Erten and Tekin (2008), Finkbeiner and Nicol (2003), Tinkham (1997), Waring (1997), and others, who have reported evidence that learning sets of semantically related words is harder than learning sets of unrelated ones. Add to this the observation that some of the verbs in collocations are also formally similar (e.g. make and take in make a drawing and take a photo; tell and talk in tell a story and talk nonsense), and it should not come as a surprise if even advanced learners produce malformed collocations in spontaneous speech.

For all these reasons, multiple encounters with a verb-noun collocation are likely to be required for the learner to establish a firm association between the particular verb and the particular noun. 
the same collocation often enough in a relatively short span of time are pretty slim, however. Extensive reading (and listening) will undoubtedly help, but the truth remains that, while collocations as a class are very common, the likelihood that one and the same collocation will be encountered several times in the same (authentic) text is very small (Boers \& Lindstromberg, 2009, pp. 42-43), and this holds true for most formulaic sequences, even those that one would imagine to be very common. For example, Byrd and Coxhead (2010, pp. 46-47) find that on the basis of occurs only twice within a corpus of written academic texts of 15,625 words.

Compared to collocation learning as a by-product of primarily message-focused activities, it seems that the deliberate learning of preselected collocations generates a faster return on investment (e.g. Laufer \& Girsai, 2008; Peters, 2009, 2012). It would appear good news, then, that more and more pedagogic materials include exercises intended to encourage the deliberate learning of collocations to make up for the otherwise slow pace of acquisition (although the term collocation is not always used in those materials). While it can be safely assumed that, on the whole, these must be beneficial in the sense that they help raise learners' (and teachers') awareness of the phenomenon of collocation in general, it needs to be acknowledged that, to date, little empirical evidence is available to support an assumption that each of the various 
exercise types presented in learning and teaching materials is optimally beneficial for learners' retention of the collocations they target. The aim of the classroom study we report further below was to help fill this gap in our knowledge.

\section{Common exercises on collocations}

We use the term 'exercise' to refer to worksheets with a focus on discrete, pre-selected language items. ${ }^{2}$ As we considered it crucial for our classroom study to have 'ecological validity' with regard to the exercises used, we manually screened the following pedagogic materials:

1. Lewis' chapter on exercises in his Implementing the Lexical Approach (1997, pp. 89-106) and Hill, Lewis \& Lewis' chapter on exercises in Teaching collocation (Lewis, ed., 2000, pp. 88-116).

2. McCarthy and O'Dell's English collocations in use (2005), which is probably the best known exercise book for learners that is entirely devoted to collocations. It is intended for self-study as well as classroom use.

3. A random sample of English vocabulary practice books: Advanced vocabulary in context (Watson, 1997), Practice vocabulary (Broukal, 2002), and Focus on vocabulary: Mastering the Academic Word List (Schmitt \& Schmitt, 2005). 
4. A random sample of EFL textbooks: Inside out (upperintermediate student's book; Kay \& Jones, 2001), Cutting edge (upper-intermediate student's book; Cunningham \& Moor, 2005), Success (intermediate student's book; McKinlay \& Hasting, 2007), Total English (advanced student's book; Wilson \& Clare, 2007), New headway (intermediate student's book; Soars \& Soars, 2009), and Four corners (student's book; Richards \& Bohlke, 2011).

We included in our sample only materials intended for intermediate+ learners, compatible with the level of the learners we planned to ask to participate in the classroom study. Plainly, our exploration of pedagogic materials for collocation exercises is not a fully- fledged corpus exploration. As mentioned, the modest aim was to check that the exercise formats we would be putting to the test in our classroom study reflected classroom reality. Before we turn to a characterization of the exercises we found most typical, it is worth mentioning that the materials for learners we surveyed vary considerably in the amount of attention they give to collocation. Of the three vocabulary books, Schmitt and Schmitt (2005) and Watson (1997) include collocation exercises in almost every unit, while Broukal's (2002) book contains only a couple of exercises on do and make collocations (pp. 157-159). Turning to the general EFL textbooks, we found only one exercise on collocations in Total English 
(p. 94) and only two in New Headway (p. 13, p. 76). The other textbooks all contain at least five exercises on collocations, but precise tallies for each of them are hard to report because at times single words as well as multiword expressions are incorporated in a single exercise.

What our perusal of the pedagogic materials does enable us to do is to identify with a reasonable degree of confidence the formats of collocation exercises that are comparatively widely used. In what follows we exemplify these formats with verb-noun collocations as the targets for learning. The examples are drawn from the study materials we developed for the classroom experiments reported further below.

The first three formats we shall put to the test in the experiments have in common that they require the learner to match verbs with nouns to form collocations. For instance, the learner may be asked to draw the right connections between the words presented in two boxes or columns (Hill, Lewis \& Lewis, 2000, pp. 109, 110; Kay \& Jones, 2001, p. 78; McCarthy \& O’Dell, 2005, pp. 43, 51, 69; McKinlay \& Hastings, 2007, p. 73; Soars \& Soars, 2009, p. 13; Watson, 1997, pp. 9, 100, 104; Wilson \& Clare, 2007, p. 94). This is illustrated by Example 1. 
Example 1

Match each of the verbs on the left with the noun on the right that it often occurs with.

$\begin{array}{ll}\text { make } & \text { attention } \\ \text { meet } & \text { a suggestion } \\ \text { pay } & \text { a deadline }\end{array}$

We shall refer to this as the 'Connect' format. The two columns or boxes need not contain the same number of words. For instance, one verb may collocate with more than one of the given nouns (e.g. Kay \& Jones, 2001, p. 25). In a variant of the 'Connect' format, all the words are jumbled in one single box from which the learner is asked to discern the collocations (McCarthy \& O’Dell, 2005, pp. 7, 45). In another variant, a group of nouns that collocate with the same verb are clustered together (Hill et al., 2000, p. 112; Schmitt \& Schmitt, 2005, p. 97; 130). Whatever the variant, the learner seems prompted in the 'Connect' format to assemble collocations from distinct building blocks rather than being stimulated to process the collocations as intact wholes from the start. According to Watson (1997, p. 8), 'The best way for students to become familiar with the way words combine is to look first only at the lists of words and to try to match them in as many ways as possible.' This is in stark contrast with recommendations that learners should be discouraged from breaking up formulaic word sequences (e.g. Gatbonton \& Segalowitz, 2005; Palmer, 1933; Wray \& Fitzpatrick, 2010). According to Lewis (2000, p. 132), 'The first task of the language teacher is to 
ensure that they are not unnecessarily taken apart.' (It is worth

mentioning, however, that many of the exercise types proposed by Lewis himself do take the target collocations apart; see below.)

It is also worth mentioning that in order for the learner to do a verbnoun matching exercise with a fair degree of success, she probably needs to be familiar with many of the target collocations already. Otherwise, the matching exercise risks turning into a guessing game.

The second format we shall put to the test is essentially a contextualized matching exercise. It presents learners with gapped sentences and a set of words to choose from to insert into the blanks (Hill et al., 2000, pp. 107, 108, 110, McCarthy \& O’Dell, 2005, pp. 33, 65, 67, 101, 119; McKinlay \& Hastings, 2007, pp. 81, 128; Watson 1997, p. 104). Example 2 illustrates this format for verb-noun collocations.

\section{Example 2}

Choose the right word to complete the blanks: give, make, pay.

- My research team have been working hard, and we are confident we will soon_a breakthrough.

- The sales representative tried to a demonstration of the efficiency of the new cleaning product.

- My husband just pretends to to him.

We shall refer to this kind of exercise as 'Insert the verb'. One advantage of this type of exercise seems to be that the learner's 
attention is drawn to the verb of the collocation, i.e. the part that has been shown to be prone to erroneous substitutions by learners. On the other hand, the exercise again requires the learner to assemble the collocations after these have been broken up into separate parts, which would appear to militate against the advantage of processing formulaic sequences holistically that is suggested in the applied psycholinguistics literature (Wray, 2002). Compared to the 'Connect' format, this exercise format appears to have the advantage of presenting the collocations in a meaningful, sentence context. It must be conceded, however, that, unless the learner is already familiar with the collocation, the sentence context is not likely to provide much of a clue for the insertion of the verb, because the verb in many verb-noun collocations is semantically not clearly restricted. For instance, while camera is likely to cue photo, it is much less likely to also cue take unless one is already familiar with the collocation take a photo in the first place. If the majority of the targeted collocations in the exercise are not yet known, choosing among the verb options may become a guessing game again.

The third popular format selected for evaluation in our study is also of the matching type, but the verb options are juxtaposed within a sentence, and the learner is required to indicate (typically by underlining) the correct one (McCarthy \& O’Dell, 2005, pp. 23, 79, 113; Richards \& 
Bohlke, 2011, p. 38), as illustrated by Example 3.

\section{Example 3}

Underline the correct verb

- Can I do / give / make a suggestion? Let's talk about this again at the next meeting, when we've had time to think about it.

- She decided to do / give / make a sacrifice and give up her job so she could look after her ill father.

- Could you do / give / make me a favour and hold my glass for a minute?

We shall refer to this format as 'Underline the verb'. Again, the advantage of this format may be the attention it draws to the verb.

Another advantage is that any wild guessing will be constrained by the limited number of choices. Sometimes, only two options are given (e.g. Broukal, 2002, p. 159; McCarthy \& O’Dell, pp. 15, 19, 25). On the other hand, it is conceivable that the layout heightens the risk of engendering undesirable verb-noun associations in the learner's mind, because the distracter verbs are presented in close proximity to the noun they are meant to be dissociated from.

The fourth exercise format that we have found to be comparatively popular differs rather fundamentally from the previous three in that it requires the learner to choose an intact collocation from a set of options (Cunningham \& Moor, 2005, p. 83; McCarthy \& O’Dell, 2005, pp. 23, 51, 121). This is illustrated by Example 4 . 
Example 4

Choose the right phrase to complete the blanks: make a suggestion, do business, pay attention.

- I'm a bit hesitant to with such a young firm.

- My husband just pretends to when I talk to him.

- Can I ? Let's take the rest of the day off.

We shall call this 'Insert the collocation'. This format appears more in accordance with the psycholinguistics literature, which suggests that the processing advantages afforded by formulaic language stem from a 'holistic' representation of formulaic sequences in memory (Wray, 2002). To do the exercise successfully, the learner also has to evaluate which sentence content matches the semantics of the given collocation. In other words, the exercise is likely to stimulate more semantic processing than the previously mentioned formats. On the other hand, the exercise does not necessarily draw the learner's attention to the choice of verb in the expressions. The strongest semantic clues needed for appropriate matching of the collocations with the sentences are provided by the nouns (e.g. business) rather than the verbs (e.g. do).

The contrast between what we could call the 'assembly line' processing promoted by the first three formats and the 'holistic' processing promoted by the fourth format will inform our main research question and predictions. Before we turn to that, however, it is necessary to point out that the exercise formats we have briefly reviewed here and will put to the test further below do not constitute a comprehensive collection. We have encountered several more types of exercises (albeit much less frequently 
than the above), such as grouping collocations as positive or negative (McCarthy \& O’Dell, 2005, p. 95), matching collocations with a definition (p. 75), putting jumbled words in the right order (p. 125), and inventing sentences that incorporate a given collocation (Schmitt \& Schmitt, 2005, p. 9). Furthermore, there are two additional formats whose popularity approximates that of the ones we have reviewed above. They are 'Correct the wrong collocations' (e.g. Hill et al., 2000, p. 107; McCarthy \& O’Dell, 2005, pp. 25, 49; McKinlay \& Hastings, 2007, p. 110) and 'Odd one out' (Hill et al., 2000, p. 113; McCarthy \& O’Dell, 2005, p. 17; McKinlay \& Hastings, 2007, p. 110). These last two types are illustrated by Examples 5 and 6 , respectively.

\section{Example 5}

Correct the wrong collocations in the following sentences.

- If you're not careful, you're going to make an accident.

- I've done a bad mistake by lying to her.

Example 6

One word in each group does not make a strong word partnership with the word in capitals. Which is the odd one?

- DO damage, harm, a favour, a breakthrough, homework

- MAKE a promise, a sacrifice, an accident, a discovery, a suggestion

While these formats may serve the purpose of raising awareness about collocation in general and perhaps also the purpose of remedying particular errors, they seem less geared towards the retention of new, correct collocations owing to the fact that these exercises direct attention in the first instance to what is not to be remembered. As the purpose of these exercise formats appears rather different from the ones 
we have described above, they will not be included in the classroom study.

\section{Research question and predictions}

The research question we address in the study below is whether the 'Insert the collocation' format yields different results in terms of learners' retention of verb-noun collocations than the three exercise formats in which collocations are assembled from building blocks (i.e. 'Connect', 'Insert the verb', and 'Underline the verb'). The study consisted of four small-scale pre-test / exercises / post-test trials. In each of the trials one or more exercise formats in which learners are asked to match verbs with their noun collocates was pitted against the exercise format in which the collocation is presented intact. The test items were gapped sentences in which the noun of the collocation (e.g. an offence), was used to cue the verb (commit), i.e. the part of the collocation that has been reported to be particularly problematic for learners.

Exercises that focus the learner's attention on the verb, like 'Insert the verb' and 'Underline the verb', may appear to have an edge when collocation knowledge is tested in this way. However, we predict that, when a learner does not already have good knowledge of many of the collocations targeted in these kinds of exercises, the confrontation with 
different options to choose from will militate against the advantages afforded by these exercise types, because the contemplation of incorrect collocates will engender unhelpful memory traces. We hypothesize that having learners work with intact, correct collocations entails less risk of erroneous verb-noun associations being planted in the learner's mind.

\section{The study}

\section{Target collocations and tests}

All the participants were given a pre-test on a set of verb-noun collocations three or four weeks prior to doing the exercises, in which the same collocations were targeted. The pre-test consisted of gapped sentences in which the participants were requested to fill in the missing verb. For example, I'm reluctant to business with such a young firm and My kids often wake me up when they nightmares. No list of verbs to choose from was given to complete the test (which distinguishes the test format from the 'Insert the verb' exercise format, where a list of verbs is given). The same test (with the sentences presented in a different order) served as post-test, which was administered at least one week after the session in which the exercises were done. It is worth noting that the test format assesses the learner's 
knowledge of what verb goes with a given noun. It does not really test productive knowledge of the verb-noun collocation as such, because the noun - the constituent that carries most meaning and that is typically of lower frequency than the verb in our targets - is given in the test items. It can thus be argued that the test format used in our study privileges the exercise formats that focus the learner's attention on the verb, i.e. the 'Insert the verb' and 'Underline the verb' exercises.

The verb-noun collocations targeted in the tests and the exercises (see Appendix 1) were all sampled from McCarthy and O’Dell (2005). In the introduction to their book (pp. 4-5), the authors explain that they selected collocations 'from those identified as significant by the Cambridge International Corpus of written and spoken English and also the CANCODE corpus of spoken English'. From that large database, collocations were selected that were deemed of high utility, 'not immediately obvious' and 'which the Cambridge Learner Corpus shows can cause problems for students'. It is not stated what level of proficiency the book is intended for, but given the fact that the same authors have produced a sequel that explicitly addresses advanced learners (McCarthy \& O’Dell, 2008), we assume it is meant for intermediate learners. 
The participants in Trial One were two intact classes of adult ESL learners taking an intensive proficiency course at a university in New Zealand. All students came from countries in South-East Asia. They had been allocated on the basis of the school's placement test to what was described by the course coordinator as intermediate proficiency classes. Only data from 19 students who participated in every stage of the data collection process (i.e. the pre-test, the exercises, and the post-test) were retained for analysis.

Table I. Learning 'gains' in Trial One (SD given in parentheses).

\begin{tabular}{|c|c|c|c|c|c|c|c|c|}
\hline & \multicolumn{4}{|c|}{$\begin{array}{l}\text { Collocations Set A } \\
\text { (maximum score: } 10 \text { ) }\end{array}$} & \multicolumn{4}{|c|}{$\begin{array}{l}\text { Collocations Set B } \\
\text { (maximum score: } 10 \text { ) }\end{array}$} \\
\hline & $\begin{array}{l}\text { Mean pre- } \\
\text { test score }\end{array}$ & $\begin{array}{l}\text { Exercise } \\
\text { format }\end{array}$ & \multicolumn{2}{|c|}{$\begin{array}{l}\text { Mean post- Mean gain I } \\
\text { test score }\end{array}$} & $\begin{array}{l}\text { Mean pre- } \\
\text { test score }\end{array}$ & \multicolumn{2}{|c|}{$\begin{array}{l}\text { Exercise } \\
\text { format }\end{array}$} & $\begin{array}{l}\text { Mean post- Mean } \\
\text { test score gain }\end{array}$ \\
\hline $\begin{array}{l}\text { Class I } \\
(n=I I)\end{array}$ & $1.82(1.72)$ & $\begin{array}{l}\text { Insert the } \\
\text { verb }\end{array}$ & $2.27(1.35)$ & 0.45 & $1.45(0$. & 93) & $\begin{array}{l}\text { Insert the } \\
\text { collocation }\end{array}$ & 2.82 (I.40) I.37 \\
\hline $\begin{array}{l}\text { Class } 2 \\
(n=8)\end{array}$ & $1.13(0.83)$ & $\begin{array}{l}\text { Insert the } \\
\text { collocation }\end{array}$ & $2.25(1.28)$ & 1.12 & 1.88 (I. & 25) & $\begin{array}{l}\text { Insert the } \\
\text { Verb }\end{array}$ & $2.38(1.06) 0.50$ \\
\hline
\end{tabular}


Two sets of 10 collocations (henceforth Set A and Set B) served as targets of exercises on counterbalanced worksheets. Set A was targeted according to the 'Insert the verb' format on the worksheet given to one class, but according to the 'Insert the collocation' format on the worksheet given to the other class. Conversely, Set B was targeted according to the 'Insert the verb' format on the worksheet given to the latter class, but according to the 'Insert the collocation' format on the worksheet given to the former.

The students tackled the exercises four weeks after taking the pretest. They were given 20 minutes to complete the exercises. After completion, the students' answer sheets were collected. In return, they received the answer key. Five minutes were given for the students to go over the answer key and to ask questions. Two weeks later, the students took the post-test. Table 1 synthesizes the pre-test to post-test comparisons.

Prior knowledge of the target collocations turned out to be minimal, with fewer than two out of 10 items known (or guessed correctly) on average. ${ }^{3}$ The students improved their score between pretest and post-test by slightly over one point on average after doing the exercise where the collocations were kept intact, and by roughly half a 
point on average after doing the exercise where a choice had to be made

from a list of verbs. This difference in gains was not significant 4 (ANCOVA: $F=0.17 ; p=0.69$ for Set $\mathrm{A}$ and $F=0.93 ; p=0.35$ for Set B). Interestingly, four students' scores regressed by two points after doing the 'Insert the verb' exercise. Three students actually wrote down a wrong verbin a post-test item (e.g. * do a deep breath) after having done that exercise while their response on the same item in the pre-test had been correct (take a deep breath). These incorrect verbs were among the options to choose from in the exercise, which suggests interference from doing that exercise. We also found one such instance of loss between pre-test and post-test after the 'Insert the collocation' exercise, though (from give a warm welcome to *make a warm welcome, with make possibly having been carried over from other collocations presented in the exercise, such as make a suggestion), which suggests that the latter may not be entirely immune to cross associations either.

\section{Trial Two}

The participants in Trial Two were from the same intact classes as in Trial One. Sixteen students took both tests and did the exercises. Two sets of 10 collocations served as targets (henceforth Set C and Set D), which were different from the ones the students worked on in Trial 
One. Collocations Set $\mathrm{C}$ was targeted for learning in the 'Underline

the verb' format on the worksheet given to one class, and in the 'Insert the collocation' format on the worksheet given to the other class.

Conversely, Set D was tackled in the 'Underline the verb' format on the worksheet given to the latter, and in the 'Insert the collocation' format on the worksheet for the former.

The students were given the exercises four weeks after taking the pretest, during regular class time. They were given 20 minutes to complete the exercises, after which their answer sheets were swapped for the answer key, which they spent five minutes studying and asking questions about. One week later, the students took the post-test, which included the 20 collocations covered by the exercises. Table 2 sums up the results of Trial Two.

Table 2. Learning 'gains' in Trial Two (SD given in parentheses).

\begin{tabular}{|c|c|c|c|c|c|c|c|c|c|c|c|c|c|c|}
\hline \multirow[b]{3}{*}{$\begin{array}{l}\text { Class I } \\
(n=9)\end{array}$} & \multicolumn{6}{|c|}{$\begin{array}{l}\text { Collocations Set C } \\
\text { (maximum score: } 10 \text { ) }\end{array}$} & \multirow[b]{2}{*}{ Mean gain } & \multicolumn{6}{|c|}{$\begin{array}{l}\text { Collocations Set D } \\
\text { (maximum score: } 10 \text { ) }\end{array}$} & \multirow{3}{*}{ Mean gain } \\
\hline & \multicolumn{2}{|c|}{$\begin{array}{l}\text { Mean pre- } \\
\text { test score }\end{array}$} & \multicolumn{2}{|c|}{$\begin{array}{l}\text { Exercise } \\
\text { format }\end{array}$} & \multicolumn{2}{|c|}{$\begin{array}{l}\text { Mean post- } \\
\text { test score }\end{array}$} & & \multicolumn{2}{|c|}{$\begin{array}{l}\text { Mean pre- } \\
\text { test score }\end{array}$} & \multicolumn{2}{|c|}{$\begin{array}{l}\text { Exercise } \\
\text { format }\end{array}$} & \multicolumn{2}{|c|}{$\begin{array}{l}\text { Mean post- } \\
\text { test score }\end{array}$} & \\
\hline & $\mathrm{I} .44(0.73)$ & $\begin{array}{l}\text { Unde } \\
\text { the } v\end{array}$ & $\begin{array}{l}\text { rline } \\
\text { erb }\end{array}$ & 2.78 & $(1.30)$ & 1.34 & 0.89 & (1.05) & $\begin{array}{l}\text { Inser } \\
\text { collo }\end{array}$ & $\begin{array}{l}\text { t the } \\
\text { cation }\end{array}$ & $1.7 \varepsilon$ & $(0.89)$ & 0.89 & \\
\hline $\begin{array}{l}\text { Class } 2 \\
(n=7)\end{array}$ & I.57 (I.62) & $\begin{array}{l}\text { Inser } \\
\text { collo } \\
\text { tion }\end{array}$ & $\begin{array}{l}t \text { the } \\
\text { ca- }\end{array}$ & 2.7 & $(1.80)$ & I. 14 & 0.71 & (0.49) & $\begin{array}{l}\text { Und } \\
\text { the }\end{array}$ & $\begin{array}{l}\text { erline } \\
\text { erb }\end{array}$ & 1.7 & $(1.50)$ & 1.00 & \\
\hline
\end{tabular}


As was the case in Trial One, the students' prior knowledge of the two sets of collocations was very limited. Overall gains between pre-test and post-test were again small, and the differences between the gains obtained via the two exercise formats are not significant (ANCOVA: $F=$ 0.08; $p=0.78$ for Set $C$ and $F=0.02 ; p=0.89$ for Set D). One could argue, perhaps, that the return on investment (however small that return was) should be considered best in the 'Underline the verb' format, because it takes less time to underline a chosen verb than to write down a complete collocation. However, while the 'Underline the verb' brought about some learning, it also seems to have had some undesirable sideeffects. Three post-test responses repeated an incorrect choice the student had made in the exercise, although the response in the pre-test had been correct.

\section{Trial Three}

Given their very small sample sizes, it is obvious that Trials One and Two require replication. Besides, considering the very poor pre-test scores, it can be argued that the proficiency level of the students and the sets of target collocations were ill matched, which raises concerns about ecological validity. Also, the types of exercises were presented on the 
worksheets in a counterbalanced fashion, so that each group of students processed half of the collocations through one type and the other half through the other type of exercise. It is possible that the inclusion of both treatments on a single hand-out caused the processing style stimulated by one exercise to spill over to the other. The focus on the verb in the verbnoun matching exercises, for example, may have led students to also pay more attention to the verb in the collocation-sentence matching exercise than they would have otherwise. In Trial Three we therefore (1) increased the sample size, (2)

Table 3. Learning 'gains' in Trial Three (SD given in parentheses).

\begin{tabular}{lllll}
\hline & $\begin{array}{l}\text { Mean pre-test } \\
\text { score } \\
\text { (maximum 30) }\end{array}$ & Exercise format & $\begin{array}{l}\text { Mean post-test } \\
\text { score (maximum 30) }\end{array}$ & Mean gain \\
\hline Class I $(n=12)$ & $17.08(3.70)$ & Insert the verb & $18.17(4.49)$ & 1.09 \\
Class 2 $(n=18)$ & $16.56(3.23)$ & Underline the verb & $18.63(4.13)$ & 2.55 \\
Class 3 $(n=16)$ & $17.44(3.72)$ & Insert the collocation & $20.81(3.03)$ & 3.37 \\
\hline
\end{tabular}

recruited participants with a higher level of proficiency, and (3) used a between-groups design where each group did collocation exercises according to only one format.

The participants were a cohort of English majors from a university in Malaysia who were following a programme at a university in New Zealand to become ESOL teachers. They were about to finish their third year of the programme, and had studied and lived in an English speaking environment for almost two years. Their level of proficiency 
was upper-intermediate to advanced. All of the students had a receptive vocabulary size of $8,000+$ word families, according to the scores they had obtained on Nation's Vocabulary Size Test (http://www.victoria.ac.nz/lals/staff/paul-nation/nation.aspx). The cohort had randomly been divided into three tutorial groups for one of their courses. The trial was integrated in their weekly tutorials for this course. Data from 46 students, who took both tests and did the exercises, were retained for analysis.

Four weeks after the pre-test, one group was given worksheets in the 'Insert the verb' format, the second group worksheets in the 'Underline the verb' format, and the third in the 'Insert the collocation' format. The worksheets targeted two sets of 15 verb-noun collocations, all of which were targets also in the pre-test/post-test. The students were given 25 minutes to do the exercises and five to ask questions about the answer key. One week later the post-test was administered. Table 3 summarizes the pre-test to post-test comparisons.

On average, students filled in correct verbs in over half of the pretest items. The differences in gains between the three treatments, which were altogether very modest, were not statistically significant (ANCOVA: $F=1.81 ; p=0.18$ )

The mean gains mentioned in Table 3 do not necessarily mean that students simply added a couple of correct responses to the number of test 
items they already got right in the pre-test. Most of the students filled in wrong verbs in some of the post-test items which they had got correct in the pre-test. This suggests that their pre-test responses on these items were not reflective of stable knowledge yet (and we cannot rule out lucky guessing, of course). It also suggests that doing the exercise failed to solidify the correct verb-noun association. Students who did the 'Insert the verb' exercises and those who did the 'Insert the collocation' exercises 'lost' on average two correct responses between pre-test and post-test. Students who did the 'Underline the verb' exercises lost 2.5 correct responses.

Our suspicion that distracter items can leave an undesirable mark in memory is aroused once again by the nature of the wrong verb substitutions in post-test items, which the students initially got right. Students who did the 'Insert the verb' exercises substituted 16 out of 31 correct pre-test choices that were lost in the post-test by a distracter verb from the exercise. No fewer than 26 out of 40 of the erroneous substitutions by students who had done the 'Underline the verb' exercises were distracter verbs from the exercises (i.e. the sentences containing three verbs from which to select the right one). For example, after having been asked in the exercise to underline the right verb in [...] give / run / take an approach [...], students would write [...] * give a new approach [...], even though they had written the 
correct verb (take) in the pre-test. Similarly, after having been asked to select the right verb in [...] hold / keep / take a watch on [...], students would write $[\ldots]$ *hold a watch on [...], even though their pretest choice had been correct (keep). Choosing the wrong option in the exercise did not appear to be a prerequisite for this kind of interference: also distracters that were not chosen by the student in the exercise turned up as responses in the post-test.

We predicted that such erroneous cross association would be less likely if collocations were presented to students as intact wholes. This is partially borne out by the data, although the 'Insert the collocation' condition is clearly not risk-free in this regard either: 12 out of the 32 instances where a correct pre-test response was lost in the post-testmay be attributable to interference from verbs from co-presented collocations. Still, the likelihood of initially correct verb choices being replaced by distracter items from the exercises was significantly greater in the group who did 'Underline the verb' exercises than the group who worked with intact collocations (Chi Square $=7.12 ; p=0.01)$.

\section{Trial Four}

Our intention in the above trials was to expose participants to treatments that are 'ecologically valid'. The implementations of the exercise formats 
can vary considerably in classroom reality, however. One dimension of variation is the number of items (e.g. gapped sentences) included in a single exercise. In McCarthy and O'Dell's (2005) book, this ranges from just four items (p. 113) to 14 (p. 67). In Hill et al. (2000) the range spans from five to 20. While the number of exercise items in the first two trials of our study seems ecologically valid, we must concede that the number of items (twice 15) in the exercises used in the third trial approaches the upper limit. Although over half of the target collocations appeared to be known by the participants, this still left a large number of items to be learned, and this may have heightened the risk of cross associations. It must also be conceded that it is unlikely that many teachers would collect their students' worksheets, replace these by an answer key, and then leave it to the students' initiative to ask questions. Instead, teachers may go through the exercises in class one item at a time, and ask students to correct answers on their worksheets in an attempt to eradicate wrong associations.

Given these considerations, we decided in Trial Four to replicate Trial Three with two changes. First, the sets of target collocations in the exercises were reduced to twice 10 items. Second, corrective feedback was given to the students after they finished the exercises and the students were asked to cross out any wrong responses on their worksheet and write the correct response instead. Only after this teacher-guided 
correction were the worksheets collected.

The participants in Trial Four belonged to a new cohort of Malaysian students in their third year of a TESOL programme at the same New Zealand University. Their level of proficiency in English was very similar to that of the students who participated in Trial

Table 4. Learning 'gains' in Trial Four (SD given in parentheses).

\begin{tabular}{lclll}
\hline & $\begin{array}{l}\text { Mean pre-test score } \\
\text { (maximum 20) }\end{array}$ & Exercise format & $\begin{array}{l}\text { Mean post- } \\
\text { test score } \\
\text { (maximum 20) }\end{array}$ & Mean gain \\
\hline Class I $(n=9)$ & $10.89(3.62)$ & Insert the verb & $13.22(2.44)$ & 2.33 \\
Class 2 $(n=8)$ & $9.75(2.25)$ & Underline the verb & $13.00(2.39)$ & 3.25 \\
Class 3 $(n=17)$ & $9.82(3.50)$ & Insert the collocation & $12.41(2.81)$ & 2.59 \\
Class 4 $(n=20)$ & $10.25(3.21)$ & Connect & $12.45(2.89)$ & 2.20 \\
\hline
\end{tabular}

Three. According to Nation's Vocabulary Size Test they all had a receptive knowledge of at least 8,000 word families. Fifty-four students took the pre-test, did the exercises and took the post-test. These were administered during the students' weekly tutorials of one of their regular courses. The cohort was randomly divided into four tutorial groups.

As in Trial Three, one group was given worksheets with exercises in the 'Insert the verb' format, the second group in the 'Underline the verb' format, and the third group in the 'Insert the collocation' format. Having four instead of three groups at our disposal this time, we decided to add one treatment to the mix: The fourth group was given work- sheets in which the collocations were targeted in the 'Connect' 
format (i.e. the format where students are required to match verbs and nouns presented to them in two columns). The exercise session followed four weeks after the pre-test, and a three-week interval separated the post-test from the exercise session. Table 4 synthesizes the pre-test to post-test comparisons.

The mean pre-test scores suggest that about half of the target collocations were known to the students before the exercise session. The post-test scores show only modestlearning gain, with the best gain obtained under the 'Underline the verb' format this time and the poorest gain obtained under the 'Connect' format. The difference in test score gains among the groups is not significant (ANCOVA: $F=0.61 ; p=$ $0.61)$.

The majority of the items which were responded to incorrectly in the pre-test stayed incorrect in the post-test, with the 'Connect' and the 'Insert the collocation' formats triggering the least change: 138 (70\%) of 197 wrong pre-test responses under the 'Connect' condition stayed wrong in the post-test, compared to $118(68 \%)$ of 173 under the 'Insert the collocation' condition, $53(64.5 \%)$ of 82 under the 'Insert the verb' condition, and $48(60 \%)$ of 80 under the 'Underline the verb' condition. This does not necessarily mean that students repeated the same incorrect verb from the pre-test, however. Often students gave new incorrect responses in the post-test, which typically corresponded to one 
of the verbs they had been confronted with in the sets of options from which to choose on their worksheets. This was especially striking in the 'Underline the verb' condition, where 18 novel wrong post-test responses (i.e. one third of the wrong post-test responses overall in this group) seem to have been 'inspired' by the distracters in the exercise. What's more, in this condition eight correct pre-test responses were substituted in the post-test by an incorrect verb, each time corresponding to a distracter on the students' exercise worksheet. For example, a student would correctly write do in Can you me a favour in the pre-test, be confronted with the choice between do, give and make in the exercise item, and subsequently write give in the post-test item. It is likely that this post-test error is due to confusion caused by the presentation in the exercise of deceptively plausible alternatives to an initially correct choice. So, although this exercise format seemed comparatively effective in triggering change, that change was clearly not always for the bet- ter. Correct pre-test responses were substituted by incorrect post-test responses also in the other groups. Five of eight test items that were 'lost' in the 'Insert the verb' condition were replaced by distracter verbs from the exercise sheet. The ratio was 10 out of 13 in the 'Connect' condition. Signs of erroneous cross associations resulting from doing the exercise were attested least in the 'Insert the collocations' condition. Still, 11 correct verbs in the pre-test 
were substituted in the post-test by an incorrect one, and in five of these instances the substitute verb had been present in one or the other of the intact collocations they had worked with on their exercise sheet. For example, one of the students displayed knowledge of the collocation conduct an investigation in the pre-test, but replaced conduct by perform in the post-test, possibly due to a cross association with perform a miracle, one of the other collocations to choose from in the exercise. It is impossible to say on the basis of these data, of course, precisely what the source of a particular post-test error is. Nevertheless, these data suggest that keeping collocations intact is no safeguard against the risk of cross associations when several collocations are presented together. The data of Trial Four do strengthen the impression left by the other three trials in our study that this risk is even greater in the case of exercises where collocations are broken up and need to be reassembled, though.

One of the novel factors in Trial Four was the corrective feedback given to the students once they had finished the exercises, and the teacher's insistence on the students' correcting mistakes on their worksheets before handing these in. The question this allows us to answer is whether wrong choices in matching exercises, which under this treatment elicit corrective feedback and thus additional attention, lead to more learning than choices that are correct from the start. To address this question, we considered all 
incorrect pre-test responses, tallied the number of correct and incorrect

responses on the corresponding matching exercise items, 5 and tallied how many times these were followed by a correct response in the corresponding post-test items. Of the 242 correct choices in the matching exercises, 90 (37\%) were followed by a correct post-test response. Of the 149 wrong choices in the matching exercises, 41 (25\%) were followed by a correct post-test response. A Chi-Square calculation shows this difference to be significant at $p=0.01$ (Yates Chi Square $=6.42$ ). It thus appears that wrong choices made while doing the matching exercise reduce the likelihood of subsequently retaining the correct verb-noun associations, despite the corrective feedback. This suggests that first created verb-noun associations inhibit the formation of alternative associations. The finding that over $37 \%$ of the wrong post-test responses in this trial repeat the same verb from the pre-test in spite of corrective modelling in the exercises adds to the plausibility of this thesis. If it is true that initially wrong associations hinder the formation of correct ones, then this raises concern over the use of exercises of the 'Correct the wrong collocations' and 'Find the odd one out' types, which we briefly mentioned earlier on, lest they create inappropriate memory traces that are hard to eradicate. 
We predicted that exercises in which verb-noun collocations are presented and manipulated as intact wholes would be less vulnerable to the formation of cross associations between the verb of one collocation and the noun of another than exercises in which students are required to assemble these collocations from distinct parts. This prediction was borne out by the four small-scale trials we have reported here. At the same time, the findings suggest that exercises in which intact collocations are co-presented are not totally immune to the formation of such unhelpful cross associations either.

As far as global test-score gains are concerned, none of the trials revealed statistically significant superiority of one exercise type over another. One reason may be that the potential advantage of drawing the learners'attention to the verb of collocations (i.e. the part of the collocation that is known to cause errors in L2 learners) afforded by the 'Insert the verb' and the 'Underline the verb' exercise formats is partly offset by erroneous verb- noun associations engendered by these formats. Our preliminary conclusion, then, is that, if one deems exercises on collocations worth the investment of time and effort, the cautious option is probably to work with worksheets which present collocations intact.

What we had not predicted was that learning gains would in general 
be as poor as they turned out to be. Moreover, it cannot be taken for granted that learning attested by means of a discrete-point test will be attested also when the learners engage in message-focused, real-time communication. The relatively small benefits that the participants in our study reaped from doing the particular exercises we gave them inevitably raises the question whether such exercises merit classroom time in the first place. This is a question that calls for future studies in which the gains obtained from such exercises are compared to those obtained by other means, such as meaning-focused input with ample repetition of the same collocations (e.g. Webb, Newton, \& Chang, 2013), textual enhancement (e.g. Bishop, 2004; Peters, 2009; 2012), awareness-raising (e.g. Boers et al., 2006; Jones \& Haywood, 2004; Stengers, Boers, Housen, \& Eyckmans, 2010), translation (e.g. Laufer \& Girsai, 2008), and teacher-guided speculations about the nonarbitrariness of word partnerships (e.g. Boers \& Lindstromberg, 2009; Liu, 2010).

There are plenty of reasons why our study needs to be replicated and complemented before anything more than preliminary conclusions can be drawn. An obvious limitation to the data we have presented here is the small number of participants per trial. We also need to acknowledge that our findings are undoubtedly influenced by the way we operationalized the different exercise formats whose effects we set 
out to compare. One dimension of variation is the number of options available to select from in the exercises. As already mentioned, the 'Underline the verb' format sometimes has just two options instead of the three we used in our study. In 'Insert the verb' exercises the number of options ranges in our sample of pedagogic materials from just two (e.g. Cunningham \& Moor, 2005, p. 131, on speak and talk) to 12 (Hill et al., 2000, p. 110; McCarthy and O’Dell, 2005, p. 103). While our own versions fell within this range, it could be argued that a version with fewer options would have reduced the risk of wrong choices in the exercises and thus the risk of erroneous associations lingering in the students' minds. This seems especially pertinent given the finding that wrong choices made at the exercise stage negatively affect post-test performance. Materials writers face the challenge of designing exercises that are neither too difficult nor too easy, that target neither too much old knowledge nor too much new information. This is a balancing act that is particularly hard if one is writing pedagogic materials for a heterogeneous population of learners. When too many of the collocations in a given exercise are new, the likelihood of blind guessing and of engendering wrong associations obviously increases. Judging by their very low pre-test scores, the participants in the first two trials of our study probably found the exercises too daunting. The participants in the third and fourth trial did seem to have a level of 
proficiency that was a better match for the exercises, but even they

faced the task of learning several new verb-noun associations in one go.

One could argue that, in order to eliminate the risk of erroneous associations entirely, all but one item of an exercise should already be known by the student. However, in that case one may also wonder whether the intended learning gain justifies the investment of doing the whole exercise in the first place.

Related to this is the degree of confusability of the words that make up the collocations targeted in a single exercise. As mentioned in the introduction, new collocations containing words that are semantically related or that are formally similar may be harder to learn if these are presented together. And yet, the collocations exercises in most of the materials we have surveyed typically target such confusable words. Even some of the units for learning designed by McCarthy and O'Dell (2005), whose book is undoubtedly well-informed by L2 vocabulary acquisition research, focus on 'everyday verbs', such as make and do (pp. 18-23) and 'synonyms and confusable words', such as close and shut (pp. 2427). As these units appear close to the beginning of the book, they probably serve the purpose of raising the learner's awareness of the tricky nature of collocations and of the need to master this dimension of language. Most of the other units present collocations joined together because they relate to the same topic (e.g. the weather) or pragmatic 
function (e.g. praising and criticizing). However, even these units cannot avoid the co- presentation of confusable verbs. It would be hard to avoid collocations with do (e.g. do athletics) alongside play (e.g. play rugby) in a unit about sports (p. 56), for instance. Many of the verbs in verbnoun collocations simply happen to be so common (e.g. make, do, take and have) that they form multiple word partnerships. It is thus inevitable that these high-frequency verbs will keep bumping into each other in different contexts, but often accompanied by a different noun-partner. In keeping with our intention to design a study with ecological validity, we did not deliberately avoid the co-presentation of potentially confusable verbs. But again, it is possible that different results might have been obtained had we taken a different approach to this.

The way exercises are incorporated in course materials is also highly likely to influence the rate of learning that is achieved. For example, McCarthy and O'Dell's (2005) design of each unit minimizes the risk of learners making wrong choices in the exercises. Per unit, the target collocations are given and exemplified on the left hand page for the learner to refer to as he or she tackles the exercises on the right hand page. This also implies that, if the learner takes in the information on the left hand page first, she will be exposed to the complete collocation before being required to reassemble it part by part in some of the exercise types. Schmitt and Schmitt (2005) also systematically present 
the learner with an integral model to be reproduced in one of their exercise formats. Some of the text books also seem to make efforts to reduce blind guessing by inserting exercises on collocations after reading and listening texts in which one or some of the targeted collocations were used, so that the learner can refer back to those uses should he or she wish to do so. However, the design feature of presenting the learner with an intact model first, before requiring him or her to tackle the exercise is by no means a regular feature of all the materials we have surveyed. Quite often, the learner is required to first draw exclusively from prior knowledge to do the given exercise, with (corrective) feedback assumedly being the instrument to bring about the actual learning (e.g. Richards \& Bohlke, 2011; Watson, 1997). Doing the exercise is not very different in that case from taking a (low-stakes) test, except that corrective feedback is given afterwards. It is clear that our classroom study mimicked the latter practice. ${ }^{6}$ Given the modest learning gains and considering the number of unhelpful remnants left in memory by wrong responses at the exercise stage evidenced by our data, it is probably not the most judicious pedagogical practice. Having said that, the findings from our study do not allow us to make any predictions about the effectiveness of the exercise formats examined if they are implemented in different ways, for instance as parts of a larger cycle of activities. 
In short, our findings should be taken to pertain to only one particular - though definitely not atypical - operationalization of the exercise types whose effectiveness we have attempted to compare. We nevertheless hope that our findings inspire further research on L2 collocation teaching, and help materials writers and teachers to make informed decisions about the design and implementation of collocation exercises. 


\section{Acknowledgements}

We are grateful also to Natasha Clark, Peter Gu, Helen Howarth, Angela Joe, Annie Marenghi, Natalia Peters, Susan Smith, Behnam Soltani, Joanne Tham, and Rebecca White at the School of Linguistics and Applied Language Studies of Victoria University of Wellington for allowing us access to their classrooms and for their help in administering the exercises and the tests. Thanks also to Seth Lindstromberg for his as always - helpful comments on an early draft of this article.

\section{Funding}

This work was supported by a grant from the Faculty of Humanities and Social Sciences of Victoria University of Wellington, New Zealand.

\section{Corresponding author:}

Frank Boers, School of Linguistics and Applied Language Studies, Victoria University of Wellington, PO Box 600, Wellington 6140, New Zealand. Email: frank.boers@vuw.ac.nz 


\section{Notes}

1. In corpus linguistics, 'collocation' usually refers to above-chance frequencies of co-occurrence of words, and it can therefore serve as an umbrella term for a plethora of word partnerships, including idioms (e.g. behind the scenes). A narrower conception maintains a distinction between collocations and idioms. The latter are then distinguished from collocations because they are considered semantically non-decomposable (i.e. their idiomatic meaning is said not to be inferable from adding up the meaning of the individual words). In the present article, we adopt this narrower conception of collocation, because that is what we have found reflected in the pedagogic materials we have surveyed and have tried to imitate. For example, McCarthy and O'Dell (2005) explicitly distinguish collocations from idioms (to which they have devoted a separate book).

2. Lewis $(1997,2000)$ distinguishes between 'exercises' and 'activities'. Activities are more interactive and/or serve the purpose of fostering learner autonomy through strategy training, for example, in consulting collocation dictionaries.

3. The mean scores in the tables include both wrong responses and zero responses, i.e. blanks that were not filled in by the students.

4. All $p$ values given in this article are two-tailed.

5. This analysis excludes the 'Insert the collocation' exercises, because only 10 exercise items in this dataset were completed incorrectly.

6. Taking a pre-test, after which no corrective feedback was given, may indeed have engendered memory traces that interfered with students' subsequence response behaviour as well. 


\section{References}

Bishop, H. (2004). The effect of typographic salience on the look up and comprehension of unknown formulaic sequences. In N. Schmitt (Ed.), Formulaic sequences: Acquisition, processing and use (pp. 227-247). Amsterdam: John Benjamins.

Boers, F., \& Lindstromberg, S. (2009). Optimizing a lexical approach to instructed second language acquisition. Basingstoke: Palgrave Macmillan.

Boers, F., Eyckmans, J., Kappel, J., Stengers, H., \& Demecheleer, H. (2006). Formulaic sequences and perceived oral proficiency: Putting a lexical approach to the test. Language Teaching Research, 10, 245-261.

Broukal, M. (2002). Practice vocabulary. Boston: Heinle \& Heinle.

Byrd, P., \& Coxhead, A. (2010). On the other hand: Lexical bundles in academic writing and in the teaching of EAP. University of Sydney Papers in TESOL, $5,31-64$.

Cunningham, S., \& Moor, P. (2005). New cutting edge. Students' book. Harlow: Pearson Education.

Dai, Z., \& Ding, Y. (2010). Effectiveness of text memorization in EFL learning of Chinese students. In D. Wood (Ed.) Perspectives on formulaic language: Acquisition and communication (pp. 71-87). New York: Continuum.

Erten, İ.H., \& Tekin, M. (2008). Effects on vocabulary acquisition of presenting new words in semantic sets versus semantically unrelated sets. System, 36, $407-22$.

Finkbeiner, M., \& Nicol, J. (2003) Semantic category effects in second language 
word learning. Applied Psycholinguistics, 24, 369-383.

Forsberg, F. (2010). Using conventional sequences in L2 French. IRAL, 48, $25-51$.

Gatbonton, E., \& Segalowitz, N. (2005). 'Rethinking communicative language teaching: A focus on access to fluency'. Canadian Modern Language Journal, 61, 325-353.

Hill, J., Lewis, M., \& Lewis, M. (2000). Strategies, activities, and exercises. In L. Lewis (Ed.), Teaching Collocation (pp. 86-117). Hove: LTP.

Jones, M., \& Haywood, S. (2004). Facilitating the acquisition of formulaic sequences: An exploratory study. In Schmitt N. (Ed.), Formulaic sequences (pp. 269-300). Amsterdam: John Benjamins.

Kay, S., \& Jones, V. (2001). Inside out. Upper intermediate student's book. Oxford: Macmillan Heinemann.

Kuiper, K., Columbus, G., \& Schmitt, N. (2009). Acquiring phrasal vocabulary. In S. Foster-Cohen (Ed.), Advances in language acquisition (pp. 216-240). Basingstoke: Palgrave Macmillan.

Laufer, B., \& Girsai, N. (2008). Form-focused instruction in second language vocabulary learning: A case for contrastive analysis and translation. Applied Linguistics, 29, 694-716.

Laufer, B., \& Waldman, T. (2011). Verb-noun collocations in second language writing: A corpus analysis of learners' English. Language Learning, 61, $647-672$.

Lewis, M. (1993). The Lexical Approach. Hove: LTP.

Lewis, M. (1997). Implementing the Lexical Approach. Hove: LTP. 
Lewis, M. (Ed.), (2000). Teaching collocation. Hove: LTP.

Li, J., \& Schmitt, N. (2010). The development of collocation use in academic texts by advanced L2 learners: A multiple case study approach. In D. Wood (Ed.), Perspectives on formulaic language: Acquisition and communication (pp. 22-46). New York: Continuum.

Liu, D. (2010). Going beyond patterns: Involving cognitive analysis in the learning of collocations. TESOL Quarterly, 44, 4-30.

McCarthy, M., \& O’Dell, F. (2005). English collocations in use. Cambridge: Cambridge University Press.

McCarthy, M., \& O’Dell, F. (2008). English collocations in use: Advanced. Cambridge: Cambridge University Press.

McKinlay, S., \& Hastings, B. (2007). Success. Intermediate student's book. Harlow: Pearson Education.

Meunier, F., \& Granger, S. (2008). Phraseology in foreign language learning and teaching. Amsterdam: John Benjamins.

Nattinger, J.R., \& DeCarrico, J.S. (2002). Lexical phrases and language teaching. Oxford: Oxford University Press.

Nekrasova, T.M. (2009). English L1 and L2 speakers' knowledge of lexical bundles. Language Learning, 59, 647-686.

Nesselhauf, N. (2005). Collocations in a learner corpus. Amsterdam: John Benjamins.

Palmer, H.E. (1933). Second interim report on English collocations. Tokyo: Kaitakusha.

Peters, E. (2009). Learning collocations through attention-drawing techniques: 
A qualitative and quantitative analysis. In A. Barfield \& H. Gyllstad (Eds.), Researching collocations in another language: Multiple perspectives (pp. 194-207). Basingstoke: Palgrave Macmillan.

Peters, E. (2012). Learning German formulaic sequences: The effect of two attention-drawing techniques. Language Learning Journal, 40, 65-79. Richards, J.C., \& Bohlke, D. (2011). Four corners. Student's book. Cambridge: Cambridge University Press.

Schmitt, N. (Ed.), (2004). Formulaic sequences: Acquisition, processing and use. Amsterdam: John Benjamins.

Schmitt, D., \& Schmitt, N. (2005). Focus on vocabulary: Mastering the Academic Word List. New York: Pearson/Longman Education.

Soars, L., \& Soars, J. (2009). New headway. Intermediate student's book. Oxford: Oxford University Press.

Stengers, H., Boers, F., Housen, A., \& Eyckmans, J. (2010). Does 'chunking' foster chunk-uptake? In S. De Knop, F. Boers, \& A. De Rycker (Eds.), Fostering language teaching efficiency through cognitive linguistics (pp. 99-117). Berlin: Mouton de Gruyter.

Tinkham, T. (1997). The effects of semantic and thematic clustering on the learning of second language vocabulary. Second Language Research, 13, $138-163$.

Waring, R. (1997). The negative effects of learning words in semantic sets: A replication. System, 25, 261-274.

Watson, D. (1997). Advanced vocabulary in context. St. Heller: Georgean Press. Webb, S., \& Kagimoto, E. (2011). Learning collocations: Do the number of 
EFFECTS ON VERB-NOUN COLLOCATIONS

collocates, position of the node word, and synonymy affect learning? Applied Linguistics, 32, 259-276.

Webb, S., Newton, J., \& Chang, A.C.S. (2013). Incidental learning of collocation. Language Learning, 63, 91-120.

Wilson, J.J., \& Clare, A. (2007). Total English. Advanced student's book. Harlow: Pearson Education.

Wood, D. (2010). Formulaic language and second language speech fluency: Background, evi-dence and classroom applications. New York: Continuum

Wray, A. (2002). Formulaic language and the lexicon. Cambridge: Cambridge University Press.

Wray, A., \& Fitzpatrick, T. (2010). Pushing learners to the extreme: The artificial use of pre-fabricated material in conversation. Innovation in Language Learning and Teaching, 4, 37-51.

Yamashita, J., \& Jiang, N. (2010). L1 influence on the acquisition of L2 collocations: Japanese ESL users and EFL learners acquiring English collocations. TESOL Quarterly, 44, 647-668. 
Appendix I. Target collocations.

\begin{tabular}{|c|c|c|c|}
\hline \multirow{2}{*}{$\begin{array}{l}\text { Collocation } \\
\text { break a promise }\end{array}$} & \multicolumn{3}{|c|}{ Trial(s) in which it was a target } \\
\hline & 3 & & \\
\hline break the silence & 3 & 4 & \\
\hline commit an offence & 3 & 4 & \\
\hline conduct an investigation & 3 & 4 & \\
\hline do business with & 2 & 3 & 4 \\
\hline do damage & 1 & & \\
\hline do harm & 2 & 3 & 4 \\
\hline do someone a favour & 2 & 3 & 4 \\
\hline do your homework & 2 & & \\
\hline draw a conclusion & I & 3 & \\
\hline give a demonstration & I & & \\
\hline give an answer & I & & \\
\hline give an impression & 2 & & \\
\hline give a warm welcome & 2 & & \\
\hline have a nightmare & 2 & 3 & 4 \\
\hline have a rest & 2 & 3 & \\
\hline have a word & 2 & 3 & 4 \\
\hline hold your breath & 2 & 3 & 4 \\
\hline keep a watch on someone & 2 & 3 & 4 \\
\hline make a breakthrough & I & 3 & \\
\hline make a contribution & I & 3 & \\
\hline make a discovery & 2 & 3 & 4 \\
\hline make a fortune & 2 & 3 & 4 \\
\hline make a promise & I & & \\
\hline make a sacrifice & 2 & 3 & 4 \\
\hline make a suggestion & 2 & 3 & 4 \\
\hline meet a deadline & 3 & 4 & \\
\hline meet a requirement & 3 & & \\
\hline pay a compliment & 2 & & \\
\hline pay attention & I & & \\
\hline pay one's last respects to & I & 3 & 4 \\
\hline pay tribute to & 3 & 4 & \\
\hline perform a miracle & 3 & 4 & \\
\hline pose a danger & I & 3 & \\
\hline raise doubts & I & & \\
\hline run a risk & 3 & & \\
\hline say a prayer & I & & \\
\hline speak a language & I & & \\
\hline take a chance & 2 & & \\
\hline take a deep breath & I & 3 & 4 \\
\hline take an approach & 2 & 3 & \\
\hline take a photo & I & 3 & 4 \\
\hline take a test & 2 & & \\
\hline take turns & 2 & 3 & \\
\hline
\end{tabular}


Appendix I. (Continued)

\begin{tabular}{|c|c|c|c|}
\hline Collocation & & was & \\
\hline talk nonsense & I & & \\
\hline tell a secret & I & & \\
\hline speak one's mind & I & & \\
\hline tell the truth & I & & \\
\hline break the silence & 3 & 4 & \\
\hline commit an offence & 3 & 4 & \\
\hline conduct an investigation & 3 & 4 & \\
\hline do business with & 2 & 3 & 4 \\
\hline do damage & I & & \\
\hline do harm & 2 & 3 & 4 \\
\hline do someone a favour & 2 & 3 & 4 \\
\hline do your homework & 2 & & \\
\hline draw a conclusion & I & 3 & \\
\hline give a demonstration & I & & \\
\hline give an answer & I & & \\
\hline give an impression & 2 & & \\
\hline give a warm welcome & 2 & & \\
\hline
\end{tabular}

